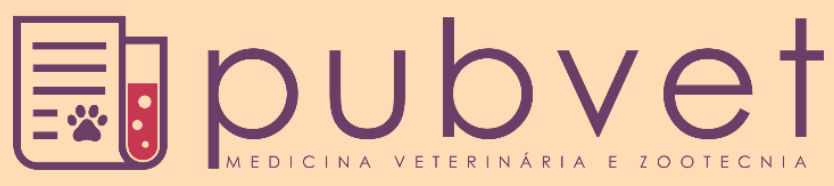

https://doi.org/10.31533/pubvet.v15n04a787.1-7

\title{
Covid-19: zoonose transmitida por animais domésticos?
}

\author{
Anderson Schrer ${ }^{1 *}$, Diego Armene Romero², Igor Silva Silito ${ }^{2} \theta$, Julia Rosenberg Pearson ${ }^{2}$, \\ Raphaella de Marchi
}

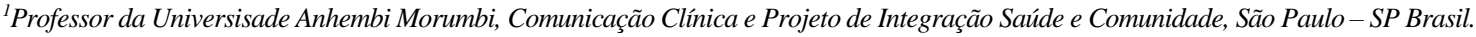
${ }^{2}$ Bacharelando em Medicina Veterinária na Universidade Anhembi Morumbi. São Paulo, SP - Brasil.

*Autor para correspondência, E-mail: asscherer@anhembi.br

\begin{abstract}
Resumo. Foi realizado um levantamento bibliográfico a respeito do atual questionamento sobre possíveis intercorrências pelo novo coronavírus (COVID-19) em espécies animais e a possibilidade da transmissão direta entre animais infectados e seres humanos. Uma revisão bibliográfica em livros, periódicos, artigos científicos, revistas eletrônicas e páginas oficiais de organizações internacionais e órgãos públicos que foram julgados pertinentes ao tema. Foi realizado com base em dados publicados Pubmed, Scielo e Google acadêmico. O estudo foi direcionado entre os casos relatados em canídeos e felinos até o dia 17 de abril de 2020. As pesquisas em andamento e as já finalizadas demonstram que o COVID-19 nas espécies domésticas manifesta-se como uma zoonose reversa, sendo gatos e furões as espécies mais propensas de contrair o vírus em relação a cães. Por meio dessa revisão bibliográfica concluiu-se que gatos e furões caso desenvolvam a doença, é de considerável menor gravidade e mortalidade ao se comparar com os casos clínicos em humanos. Já os cães parecem ter baixíssimos índices de contratilidade do vírus e não aparentam correr risco de saúde diante da atual pandemia.
\end{abstract}

Palavras-chave: zoonose, animais domésticos, COVID-19

\section{COVID-19: Zoonosis transmitted by dogs and cats?}

\begin{abstract}
A bibliographic survey was conducted regarding the current questioning about possible complications from the new coronavirus (COVID-19) in animal species and the possibility of direct transmission between infected animals and humans. A bibliographic review of books, periodicals, scientific articles, electronic journals, and official pages of international organizations and public bodies that were considered relevant to the topic. Databases like Pubmed, Scielo, and Google Scholar were used as a base. The study was directed among the reported cases in dogs and cats until April 17th, 2020. The ongoing researches and those already concluded demonstrate that COVID-19 in domestic species manifests itself as a reverse zoonosis, with cats and ferrets being the most common species more likely to contract the virus when compared to dogs. Through this bibliographic review it was concluded that if cats and ferrets develop the disease, the complications are considerably less severe and mortal when compared to clinical cases in humans. Dogs, on the other hand, seem to have extremely low levels of contractility of the virus and do not appear to be at risk in the face of the current pandemic.
\end{abstract}

Keywords: zoonosis, domestic animals, COVID-19

\section{Introdução}

Em dezembro de 2019, após a ocorrência de algumas mortes suspeitas na província de Wubei, na China, em habitantes que haviam frequentado um mercado de frutos do mar e animais vivos, uma preocupação se espalhou entre os continentes. Posteriormente, o sequenciamento do genoma do vírus 
permitiu a detecção da similaridade ao SARS-COV (coronavírus da síndrome respiratória aguda grave), vírus da família Coronaviridae que levou a óbito mais de 8000 pessoas. Diante desses fatos e com surtos de casos ao redor do mundo, a Organização Mundial da Saúde (OMS), em 11 de março de 2020, declarou se tratar de uma pandemia.

Diante dos fatos e da recorrente associação com morcegos, além do reconhecimento da presença de Cepas de coronavírus associadas a espécies domésticas (Coronavírus canino de sintomatologia entérica - CCoV e peritonite infecciosa felina - PIF), criou-se no senso comum, a dúvida acerca da possibilidade do COVID-19 se tratar de uma zoonose, acometendo os animais, mas potencialmente transmissível a humanos. Assim, o objetivo desse artigo é transmitir informações fidedignas e de aspecto científico às pessoas, buscando sanar eventuais dúvidas e explanar os rumos da ciência em meio a esta crise de saúde pública. Junto a isso, vale ressaltar a necessidade em abordar uma temática que, em meio às incertezas científicas, abre margem à rede de informações divulgadas pelo senso comum, cuja ausência de veracidade e de fontes confiáveis pode causar pânico e muitas vezes levar o tutor ao abandono de seu animal ou a má execução de medidas de prevenção. Ademais, busca colaborar para enriquecer o repertório literário da comunidade científica.

De acordo com os relatórios publicados pela American Journal of Public Health, zoonoses são as doenças que são naturalmente transmitidas de animais vertebrados para o Homem (Steele, 1973). Todavia, após a Organização Mundial da Saúde (2020) declarar, que está em curso uma pandemia (disseminação de doença a nível global) pelo novo Coronavírus, veio-se à tona o questionamento: "o Coronavírus é uma zoonose transmitida por cães e gatos?".

\section{Conforme recomendação da World Small Animal Veterinary Association - WSAVA (2020):}

Ao tratar de um vírus pouco conhecido e que até o momento não há relatos de casos acometendo animais domésticos, o recomendado para pessoas que testarem positivo para a doença é que mantenham distanciamento de seus animais, tendo em vista a possibilidade de o vírus sofrer mutações e passar a acometer diferentes espécies.

Vale ressaltar que os vírus do gênero Alphacoronaviridae que afetam felinos e caninos, dentre outras espécies, não são transmissíveis aos humanos e em nada se relaciona ao COVID-19.

Recentemente, circulou em diversos veículos de informação, um possível caso de um cachorro chinês que teve resultado positivo para a patologia em questão, repercutindo um grande desentendimento e notícias falsas sobre o tema. De acordo com o médico veterinário virologista Paulo Brandão, Professor Doutor da Faculdade de Medicina Veterinária e Zootecnia da Universidade de São Paulo, FMVZ-USP, 2020, o animal pode ter sido apenas um hospedeiro acidental, incapaz de transmitir o vírus para humanos e apresentar sinais clínicos. A presença de vírus na saliva do animal pode estar relacionada ao contato próximo com o tutor contaminado.

A subfamília Coronavirinae, família Coronaviridae, da ordem Nidovirales é responsável pela Síndrome Aguda Grave, sendo subdividida nos gêneros Alfacoronavírus, Betacoronavírus, Gamacoronavírus e Deltacoronavírus. Causa, em animais, lesões nos sistemas hepático, respiratório, gastrointestinal e neurológico. Em humanos, afeta principalmente o sistema respiratório superior. $\mathrm{O}$ gênero Coronavírus é subdividido em três grandes grupos, baseando-se em propriedades genéticas e sorológicas. Incluem-se em cada um desses grupos, agentes patológicos que afetam cães, gatos, suínos, ratos, murinos, aves (frango e peru), bovinos e humanos (Fundação Osvaldo Cruz, 2020).

O trabalho visa formular uma revisão de literatura, sendo realizadas buscas bibliográficas sobre a temática em livros, periódicos, artigos científicos, revistas eletrônicas e páginas oficiais de organizações internacionais e órgãos públicos nas bases de dados eletrônicas Pubmed, Scielo e Google acadêmico.

Na sequência, serão apresentadas as particularidades da família Coronaviridae, que compreende as principais espécies de vírus que acometem cães, gatos e humanos.

\section{Gênero Alphacoronaviridae}

Este gênero é responsável por causar gastroenterite (diarreia e vômito), peritonite e doenças respiratórias em felinos, cães, humanos e suínos. As principais espécies são: vírus da gastroenterite transmissível (TEGV), coronavírus canino (CCV), coronavírus respiratório porcino (PRCV), 
coronavírus felino (FECV), vírus da diarreia epidêmica porcina (PEDV), peritonite infecciosa felina (FIPV) e coronavírus humano 229E (HCV-229E) e NL63 (HCV-NL63). Estas espécies fundiram-se neste gênero, baseando-se na semelhança entre sequências de nucleotídeos do genoma e na organização.

Como visto, em cães, o vírus pode manifestar-se de duas diferentes formas, uma com manifestação respiratória e outra entérica, levando a casos de diarreia. Em 1989 foi identificado pela primeira vez no Brasil o CCoV, sendo possível a inclusão da vacina contra o coronavírus entérico nas opções múltiplas em todo o país (V8, V10, V11 e V12) Reis (2021)

Já os felinos, podem ser portadores do vírus, desenvolvendo a peritonite infecciosa felina (PIF), muito comum em todo o mundo e, principalmente, em abrigos e gatis. No entanto, ainda não há vacinas para a PIF, fazendo-se necessária a adoção de boas práticas de manejo, como manter o gato dentro de casa, evitar contato com animal desconhecido e adquiri-lo em abrigos negativos para PIF.

Diante do exposto, faz-se necessário ressaltar que o CCoV e o FCoV são vírus não transmissíveis a espécie humana, assim como os vírus que acometem os suínos. Em relação ao coronavírus $229 \mathrm{E}$ e o coronavírus NL63, o Ministério da Saúde (2020) informa que foram isolados pela primeira vez em 1937 e em 1965 passou a ser descrito como coronavírus, em decorrência do perfil molecular, muito semelhante a uma coroa. Assim, causam múltiplas infecções ao longo da vida, comum entre as crianças pequenas. Enfim, nada tem a ver com o COVID-19.

\section{Gênero Betacoronaviridae}

Os Betacoronavírus, assim como os demais gêneros da família Coronaviridae, são vírus de RNA de cadeia simples, compostos de linhagens virais variadas, de sentido positivo e origem zoonótica. Os BetaCovs de maior importância clínica para humanos são HKU1 e OC43 (linhagem A), ambos com RNA de fita simples capaz de entrar nas células hospedeiras por meio de ligações com o receptor ácido Nacetilneuramínico. O primeiro foi identificado pela primeira vez em janeiro de 2005, tendo seu genoma identificado e assemelhado ao vírus da hepatite do camundongo (MHV). Já o segundo, de acordo com Lau et al. (2011) possui uma proteína de superfície adicional, a hematoglutinina esterase, relacionada ao resfriado comum.

$\mathrm{Na}$ linhagem C, tem-se a síndrome respiratória do oriente médio (MERS-CoV) e, na linhagem B, a (SARS-CoV) onde, de acordo com a World Organisation for Animal Health - (OiE, 2020), o primeiro é transmitido pelas civetas para humanos e o segundo pelos dromedários e camelos. O SARS-CoV foi identificado pela primeira vez em 2002, com casos identificados também em 2003 e 2004, com letalidade de 10\%. De acordo com o Departamento Científico de Infectologia (2020), houve 8096 casos em 29 países, com 774 vítimas fatais. Já a cepa MERS-CoV foi identificada pela primeira vez em 2012, na Arábia Saudita: o paciente manifestava pneumonia severa e alterações renais. Ainda de acordo com o departamento, foram registrados 2494 casos em 27 países e 858 mortes.

\section{Gênero Gammacoronaviridae}

O gênero Gammacoronaviridae é responsável por causar bronquites infecciosas em aves (IBV) e alterações gastrointestinais, como diarreia em perus, além de novas cepas de Coronavírus que, advindo da IBV, também atinge patos e alguns tipos de mamíferos. Não há, até o presente momento, identificação de transmissão entre vírus desse gênero e a espécie humana, mantendo o contágio apenas em animais silvestres de acordo com Xavier \& Gonçalves (2020).

\section{Gênero Deltacoronaviridae}

Este gênero tem como principal representante o Deltacoronavírus porcino (PDCoV) que de acordo com Boley et al. (2020), do Centro de Controle e Prevenção de Doenças (CDC), possui origem desconhecida, mas devido a prevalência de $\mathrm{DCoV}$ em pássaros e similaridades gênomicas, os pesquisadores suspeitam que o PDCoV pode ter se originado de um DCoV ancestral das aves.

Este vírus foi inicialmente detectado em amostras fecais de porcos asiáticos em 2009, tendo sua etiologia identificada após diarreias em rebanhos nos Estados Unidos, em 2014. Ainda, segundo a CDC, não se sabe ao certo a forma de transição, mas estudos in vitro mostraram que a PDCoV utiliza uma 
região conservada da proteína aminopeptidase $\mathrm{N}$, infectando linha de células de diversas espécies. Com essa característica, este, tornou-se um potencial patógeno zoonótico.

\section{COVID-19}

Em dezembro de 2019, alguns casos de pneumonia de origem desconhecida, passaram a ser relatados na península de Wubei, China, em pacientes que tiveram contato com um mercado de frutos do mar e animais vivos. Após o sequenciamento do genoma deste novo vírus, mostrou-se que, ainda de acordo com a Sociedade de Pediatria, $75 \%$ a $80 \%$ é idêntico ao SARS-CoV, doença já mencionada anteriormente, e ainda mais intimamente relacionado ao morcego. Segundo a OiE (2020), esse vírus é encontrado na circulação sanguínea de populações do morcego Rhinolophus, sendo um possível transmissor intermediário do vírus. Este vírus da família Coronaviridae foi nomeado SARS-CoV-2, também chamado COVID-19, ou apenas Coronavírus.

Tomando por base a $\mathrm{OiE}(2020)$ :

Agora que as infecções pelo COVID-19 estão amplamente distribuídas na população humana, existe a possibilidade de alguns animais serem infectados através do contato próximo com humanos. Até o momento, dois cães foram infectados com o vírus COVID-19, após contato próximo com humanos infectados. Um gato também testou positivo após uma exposição rigorosa ao dono positivo.

Estão em andamento diversas pesquisas com o intuito de traçar as espécies suscetíveis ao vírus e de que forma o vírus se manifestaria no organismo animal. Devido às incertezas, o recomendável é que pessoas que testarem positivo evitem contato com animais, mantendo cuidados básicos de higiene.

O artigo publicado na biorxiv em 7 de abril de 2020, relata o teste feito em 21 animais ( 9 gatos e 12 cachorros), selecionados de maneira aleatória. Dois dos tutores dos animais testaram positivo para COVID-19. Destes 21 animais, nenhum apresentou formação de anticorpo positivo (Temmam et al., 2020).

Em 8 de abril de 2020, saiu uma pesquisa publicada na Science, testando a suscetibilidade de contração do vírus entre espécies. Todos os animais foram submetidos a exposição intensa e inoculados ao vírus e foram monitorados por exames físicos e testes de sorologia. Nela, foi concluído que gatos e furões são mais prováveis de o teste de sorologia dar positivo (Figura 1 e 2), e que são baixos os índices de contração em cães (Shi et al., 2020), como evidenciam os gráficos abaixo:
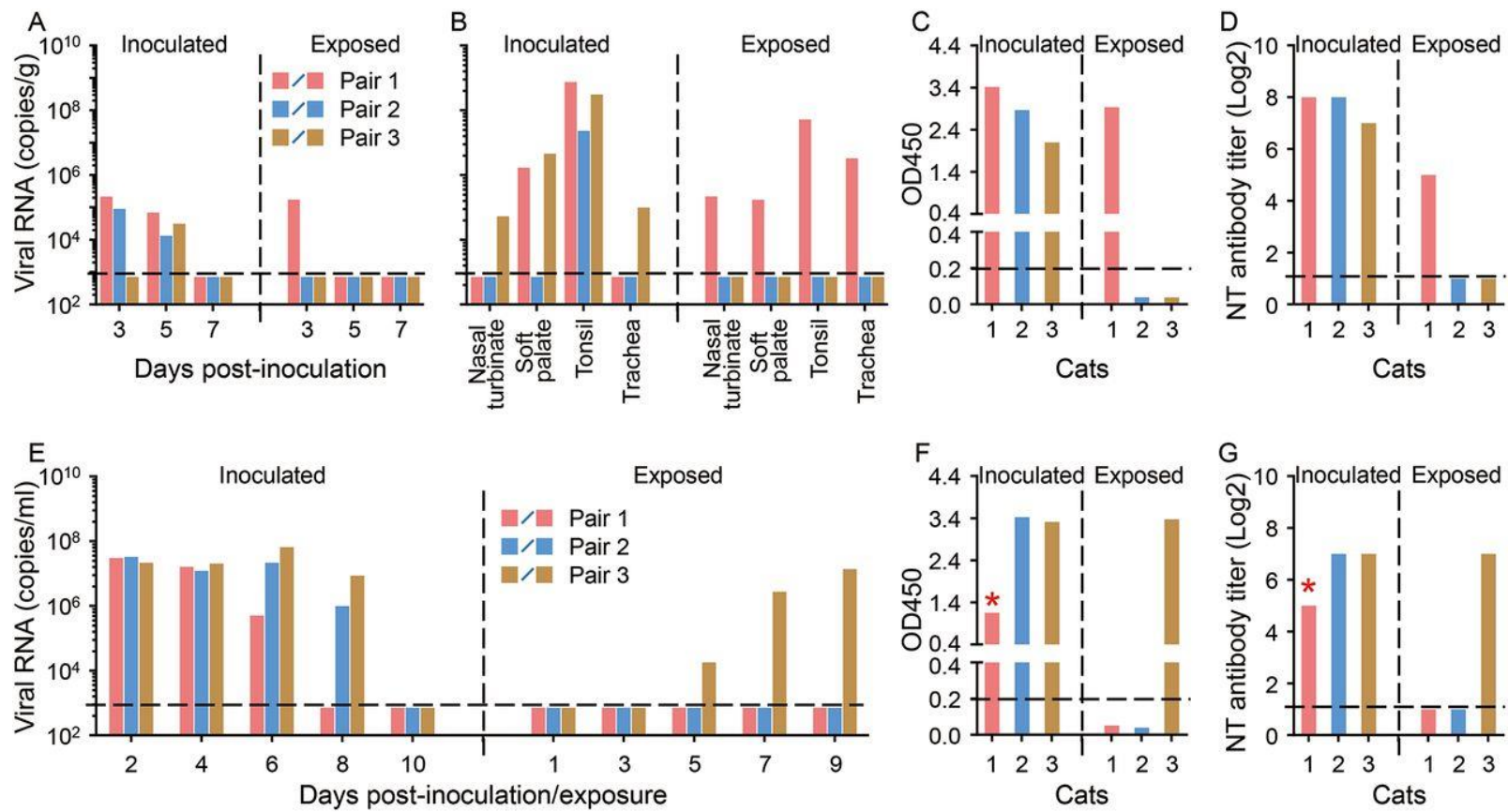

Figura 1. Relação entre a presença do RNA do vírus em relação aos dias nos gatos Fonte: Shi et al. (2020). 
Também na biorxiv, foi publicada em 1 de abril de 2020 um artigo que explicava um experimento feito na China, onde 102 gatos foram testados e $15(14,7 \%)$ destes deram positivo para a sorologia e 11 $(10,8 \%)$ deram positivo para presença de anticorpos neutralizadores (Zhang et al., 2020).

Com o passar do tempo, foram registradas diversas sorologias positivas em animais como gatos, furões, cães, tigres, hamsters e primatas, mas de acordo com os relatos de caso e análise publicados pela Cell Host \& Microbe, os furões parecem ser um especial grupo de risco e isso deve ser levado em consideração na hora de avaliar os casos clínicos. O artigo fala como a espécie sofreu muito em contato com outros vírus como o MERS-Cov e o SARS-Cov, e como isso predispõe a espécie a maior contração do vírus quando em contato com o SARS-Cov 2. O maior destaque é a facilidade de contaminação entre si e como esse vírus pode representar um grande risco para a espécie, visto que o novo coronavírus causa sintomas febris e até mesmo problemas respiratórios (Kim et al., 2020).
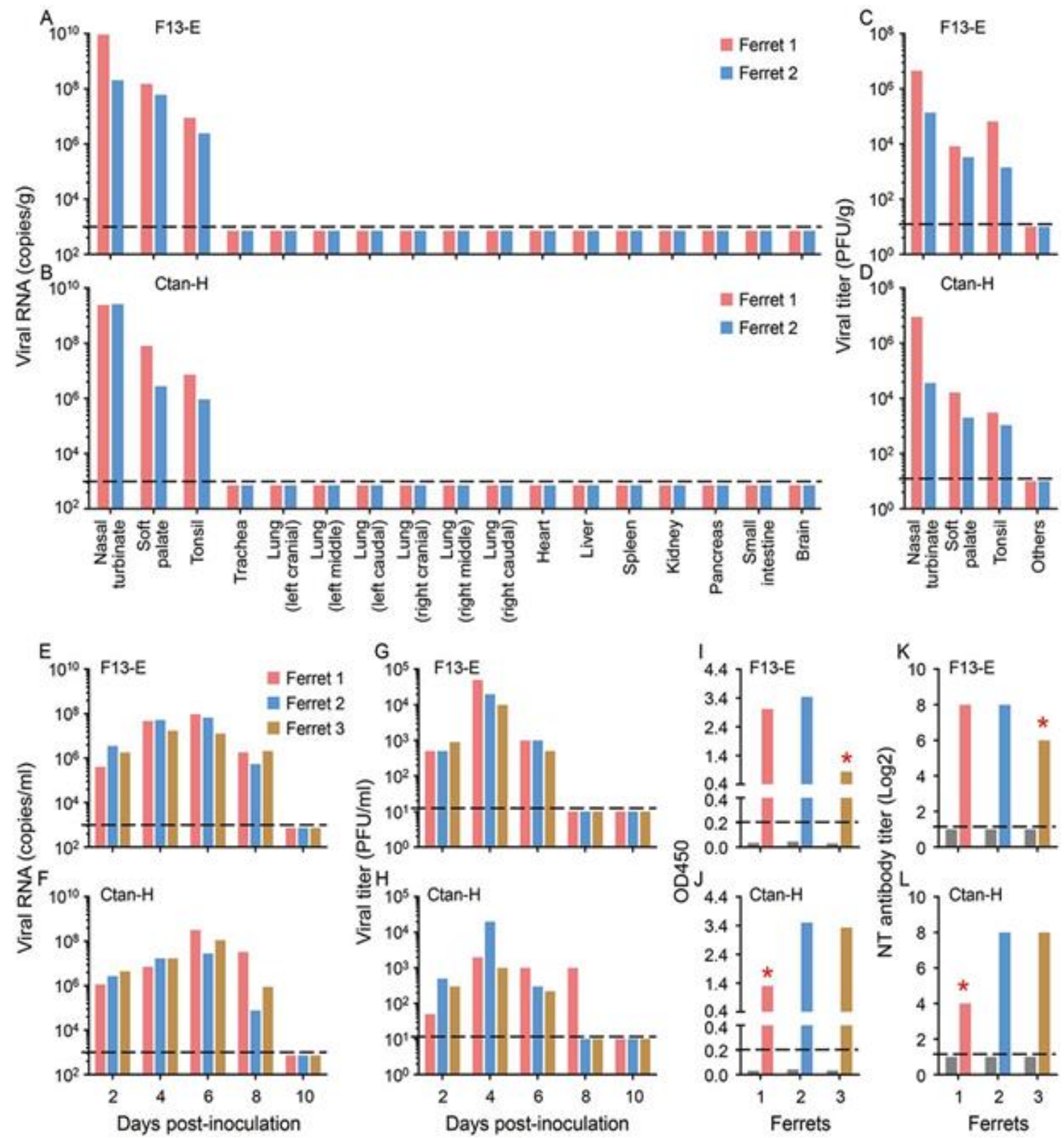

Figura 2. Relação entre a presença do RNA do vírus em relação aos dias em furões. Ele também retrata as regiões do corpo em que o vírus foi localizado. Fonte: Shi et al. (2020).

Seguindo na mesma preocupação, no dia 9 de junho de 2020, foi anunciado na Science que milhares de visões (animais de considerável semelhança aos furões) que são produzidos na Holanda para a produção de casacos foram eutanasiados por terem contraído o SARS-Cov 2. O governo Holandês 
declarou ter sido uma medida de saúde pública, por mais que não existem evidências de que animais transmitam o vírus para humanos (Enserink, 2020).

De maneira geral, são publicados regularmente resultados de pesquisas a respeito. Alguns declaram presença e manifestação do COVID-19 enquanto outros indicam contágio, porém não manifestação da doença na maioria das espécies. No dia 17 de abril de 2020, foi transmitida uma live reunindo especialistas de renome discutindo a implicância do COVID-19 na veterinária e fazendo uma coletânea e análise das informações e artigos que até aquele momento haviam sido publicados (WSAVA, 2020). Nessa transmissão, conclui-se que, de maneira geral, gatos e furões tem maiores chances de contrair o vírus em relação aos cães, porem sua manifestação é improvável e de gravidade muito menor do que a humana. Também foi anunciado que há sim a transmissão de humanos para os animais, mas que o contrário não ocorre, e que o COVID-19 está no processo de ser declarado como uma zoonose reversa (WSAVA, 2020). O COVID-19, também referido como SARS-CoV 2, ser declarado como uma zoonose reversa demonstra que não apresenta risco de transmissão do vírus para humanos via animais, e sim o contrário.

Em suma, gatos e furões estão mais propensos à contração do vírus, mas as evidências são controvérsias quanto ao desenvolvimento da doença ou não, reforçando a preocupação em furões. O que se sabe, é que, caso haja desenvolvimento da doença, é de considerável menor gravidade e mortalidade ao se comparar com os casos clínicos em humanos. Cachorros parecem ter baixíssimos índices de contratilidade do vírus e não aparentam correr risco de saúde diante da atual pandemia.

Diante do atual cenário internacional, é esperado que dúvidas surjam a respeito da implicação do COVID-19 na veterinária. É importante ressaltar que é uma temática em constante desenvolvimento e alterações e que esta revisão de literatura é referente às informações coletadas até o dia 18 de junho de 2020, e que essas informações estão sujeitas a atualizações ou até mesmo invalidações após esta data.

\section{Referências}

Boley, P. A., Alhamo, M. A., Lossie, G., Yadav, K. K., Vasquez-Lee, M., Saif, L. J., \& Kenney, S. P. (2020). Porcine Deltacoronavirus Infection and Transmission in Poultry, United States1. Emerging Infectious Diseases, 26(2), 255-265. https://doi.org/10.3201/eid2602.190346

Departamento Científico de Infectologia. (2020). Novo coronavírus (COVID-19). Socieade Brasileira de Pediatria, $12 . \quad$ https://www.sbp.com.br/fileadmin/user_upload/22340d-DocCientifico__Novo_coronavirus.pdf

Enserink, M. (2020). Coronavirus rips through Dutch mink farms, triggering culls. Science, 368(6496), 1169 LP - 1169. https://doi.org/10.1126/science.368.6496.1169

Fundação Oswaldo Cruz. Coronavírus. Disponível em: http://www.invivo.fiocruz.br/cgi/cgilua.exe/sys/start.htm?infoid=1438\&sid=8. Acesso em: $01 \mathrm{mar}$. 2021.

Kim, Y.-I., Kim, S.-G., Kim, S.-M., Kim, E.-H., Park, S.-J., Yu, K.-M., Chang, J.-H., Kim, E. J., Lee, S., Casel, M. A. B., Um, J., Song, M.-S., Jeong, H. W., Lai, V. D., Kim, Y., Chin, B. S., Park, J.-S., Chung, K.-H., Foo, S.-S., ... Choi, Y. K. (2020). Infection and Rapid Transmission of SARS-CoV2 in Ferrets. Cell Host \& Microbe, 27(5), 704-709.e2. https://doi.org/10.1016/j.chom.2020.03.023

Ministério da Saúde. Resposta Nacional e Internacional de Enfrentamento ao Novo Coronavírus. 2020. Disponível em: https://coronavirus.saude.gov.br/resposta-brasileira-a-emergencia\#tinterna. Acesso em: 01 mar. 2021.

Lau, S. K. P., Lee, P., Tsang, A. K. L., Yip, C. C. Y., Tse, H., Lee, R. A., So, L.-Y., Lau, Y.-L., Chan, K.-H., Woo, P. C. Y., \& Yuen, K.-Y. (2011). Molecular Epidemiology of Human Coronavirus OC43 Reveals Evolution of Different Genotypes over Time and Recent Emergence of a Novel Genotype due to Natural Recombination. Journal of Virology, 85(21), 11325-11337. https://doi.org/10.1128/JVI.05512-11

OiE. (2020). Questions and Answers on COVID-19. World Organisation for Animal Health. https://www.oie.int/scientific-expertise/specific-information-and-recommendations/questions-andanswers-on-2019novel-coronavirus

Organização mundial da Saúde (2020). COVID-19 é agora caracterizada como pandemia. Disponível 
em: $\quad$ https://www.paho.org/bra/index.php?option=com_content\&view=article\&id=6120:omsafirma-que-covid-19-e-agora-caracterizada-como-pandemia\&Itemid=812. Acesso em: 01 mar. 2021.

Reis R. (2021). Coronavirose canina - o que precisamos saber. Disponível em: https://www.zoetis.com.br/prevencaocaesegatos/posts/c\%C3\%A3es/coronavirose-canina\%E2\%80\%93-o-que-precisamos-saber.aspx\#. Acesso em: 01 mar. 2021.

Shi, J., Wen, Z., Zhong, G., Yang, H., Wang, C., Huang, B., Liu, R., He, X., Shuai, L., Sun, Z., Zhao, Y., Liu, P., Liang, L., Cui, P., Wang, J., Zhang, X., Guan, Y., Tan, W., Wu, G., ... Bu, Z. (2020). Susceptibility of ferrets, cats, dogs, and other domesticated animals to SARS-coronavirus 2. Science, 368(6494), 1016-1020. https://doi.org/10.1126/science.abb7015

Steele, J. H. (1973). A bookshelf on veterinary public health. American Journal of Public Health, 63(4), 291-311.

Temmam, S., Barbarino, A., Maso, D., Behillil, S., Enouf, V., Huon, C., Jaraud, A., Chevallier, L., Backovic, M., Pérot, P., Verwaerde, P., Tiret, L., van der Werf, S., \& Eloit, M. (2020). Absence of SARS-CoV-2 infection in cats and dogs in close contact with a cluster of COVID-19 patients in a veterinary campus. BioRxiv, 2020.04.07.029090. https://doi.org/10.1101/2020.04.07.029090

WSAVA. (2020). 'COVID-19 and Companion Animals - What we know today.' WSAVA Webinar to Set out Latest Thinking and Offer Advice for Veterinarians. https://wsava.org/wpcontent/uploads/2020/04/COVID-19-and-Companion-Animals-What-we-know-today.pdf

Zhang, Q., Zhang, H., Huang, K., Yang, Y., Hui, X., Gao, J., He, X., Li, C., Gong, W., Zhang, Y., Peng, C., Gao, X., Chen, H., Zou, Z., Shi, Z., \& Jin, M. (2020). SARS-CoV-2 neutralizing serum antibodies in cats: a serological investigation. BioRxiv, 2020.04.01.021196. https://doi.org/10.1101/2020.04.01.021196

Xavier, G. \& Gonçalves, L. (2020) Coronavírus em aves: Bronquite infecciosa das galinhas (BIG). Veterinária consultoria júnior UFMG. Disponível em: https://www.vetjr.com/post/coronav\%C3\%adrus-em-aves-bronquite-infecciosa-das-galinhas-big. Acesso dia 03 mar .2021

\section{Histórico do artigo:}

Recebido: 2 de outubro de 2020 . Aprovado: 24 de outubro de 2020. Disponível online: 16 de março de 2021.
Licenciamento: Este artigo é publicado na modalidade Acesso Aberto sob a licença Creative Commons
Atribuição 4.0 (CC-BY 4.0), a qual permite uso irrestrito, distribuição, reprodução em qualquer meio, desde que o autor e a fonte sejam devidamente creditados. 